\title{
Cost-effectiveness analysis of OM-85 vs placebo in the prevention of acute respiratory tract infections (ARTIs) in children that attend day-care centers
}

\author{
Arturo Berber ${ }^{1}(0)$ and Blanca Estela Del-Rio-Navarro ${ }^{2 *}$
}

\begin{abstract}
Background: Children that attend day-care centers frequently contract acute respiratory tract infections (ARTIs). ARTIs represent a burden for both children and parents. Systematic reviews on the use of immunostimulants for the prevention of juvenile recurrent ARTIs have provided moderate evidence of efficacy and safety. The aim of the study was to establish whether the immunostimulant, OM-85, was cost-effective in preventing ARTIs in children 26 years old that attended day-care centers or preschools in Mexico. We performed a systematic review to evaluate the efficacy of OM-85. For costs, we assumed an institutional perspective, which included the costs of care and supplies over a study period of six months, during the autumn-winter seasons. We created decision trees and constructed a model to identify pharmacoeconomic parameters. We generated 1000 estimations with the bootstrap method to calculate descriptive statistics of pharmacoeconomic parameters. We evaluated costeffectiveness compared to treatment without immunostimulants.

Results: The mean (SD) incidences of ARTIs were $5.59 \pm 0.29$ without immunostimulants and $2.97 \pm 0.32$ with OM85 , during the study period. The mean (25th, 75th percentile) direct costs of ARTls were $57.04(37.11,76.39)$ US\$ (US dollars) without immunostimulants and $48.53(37.35,58.93)$ US\$ with OM-85, with a mean increment of $-8.51(-17$. $08,0.75)$ US\$, and a mean cost-effectiveness of $-17.94(-36.48,1.66)$ US\$. The direct costs plus the cost of one parent missing work to care for the child with ARTI were $125.76(102.83,150.16)$ US\$, without immunostimulant and $85.21(72.15,98.81)$ US\$, with OM-85. The increment was $-40.55(-68.29,-13.95)$ US\$, and the cost-effectiveness was $-86.89(-142.37,-29.34)$ US\$.Part of the cost reduction was ascribed to the reduced use of medications, particularly antibiotics.

Conclusions: Our results were consistent with previous clinical studies conducted in closed institutions in Mexico. OM-85 reduced the number of ARTIs and the frequency of antibiotics use. We concluded that OM-85 was costeffective for preventing ARTIs in children that attended day-care centers, particularly when parental absenteeism was covered by the institutions.
\end{abstract}

Keywords: Acute respiratory tract infection, Prevention, Day-care-center, Immunostimulant, OM-85

\footnotetext{
* Correspondence: blancadelrionavarro@gmail.com

${ }^{2}$ Allergy \& Immunology Service, Hospital Infantil de Mexico "Federico

Gomez", Dr. Marquez 162, CP 06720 Mexico City, Mexico

Full list of author information is available at the end of the article
}

(c) The Author(s). 2019 Open Access This article is distributed under the terms of the Creative Commons Attribution 4.0 International License (http://creativecommons.org/licenses/by/4.0/), which permits unrestricted use, distribution, and reproduction in any medium, provided you give appropriate credit to the original author(s) and the source, provide a link to the Creative Commons license, and indicate if changes were made. 


\section{Background}

Children that attend day-care centers are at increased risk of contracting an acute respiratory tract infection (ARTI). A systematic review on the children that attend day-care centers found elevations in the relative risk (RR) of upper ARTIs (RR: 1.88), acute otitis media (RR: 1.58), and lower ARTIs (RR: 2.10) [1]. For instance, in a Mexican study of children aged 1.5 to 4 months, the ARTI incidence was 6 episodes per year, with a median of 40 sick-days, in those staying at home; in contrast, children in day-care centers experienced 14. ARTIs per year, with 74 sick-days [2]. Additionally, the cost of ARTI treatments was calculated to be twice as high for children in day-care centers as the cost for children not in day-care centers [3]. Similarly, in Chile, for a cohort of children attending a day-care center, the total cost per ARTI was US\$ 129.00 for infants and US\$ 53.00 for toddlers; the cost contributed by parents missing work to care for a sick child (parental job absenteeism) were US\$ 105.00 (81\% of the total cost), for infants, and US\$ 38.00 (71\% of the total cost), for toddlers [4].

OM-85 is a lyophilized bacterial lysate that comprises 21 bacterial strains used in the prevention of ARTIs. OM-85 was previously tested in twelve double-blind placebo control clinical trials in children [5-16]; of those trials, seven showed efficacy, where the effect was expressed as the percentage difference in the number of ARTIs compared to placebo [5, 7, 9, 10, 12, 13, 16]. A Cochrane systematic review found that OM-85 had an effect of $-35.90 \%$ (range: $-49.46,-22.35 \%$ ) [17]. Their meta-analysis included randomized controlled trials (RCTs) and compared the ability of immunostimulants, administered by any method, to prevent ARTIs, compared to placebo. Trial participants were under 18 years of age with no allergic or chronic conditions. The studied outcomes comprised the differences between groups in the number of ARTIs, the percentage of ARTIs, and the incidence of adverse events in children. The submeta-analysis of OM-85 [16] included studies by Ahrens (1984) [5], Del-Rio-Navarro (2003) [7], Gomez-Barreto (1998) [8], Gutierrez-Tarango (2001) [9], Jara-Perez (2000) [10], Maestroni (1984) [11], Schaad (1986) [14], Schaad (2002) [15], and Zagar (1988) [16].

Another meta-analysis that considered only Mexican studies (Del-Rio-Navarro (2003) [7], Gomez-Barreto (1998) [8], Gutierrez-Tarango (2001) [9], and Jara-Perez (2000) [10]) calculated an effect of $-46.85 \%$ (-54.98, 38.72) [18]. This same systematic review reported that immunostimulants for ARTI prevention in children caused gastrointestinal adverse events, with a global incidence of 30 per 1000 treated children (95\% confidence interval (CI): 11, 50), and skin adverse events, with an incidence of 7 per 1000 (95\% CI: -8, 14) [17].

\section{Study objective}

We aimed to establish whether the immunostimulant, OM-85 compared to placebo, was cost-effective for the prevention of ARTIs in preschool-age children (aged 2 to 6 years) that attended day-care centers and preschools in Mexico. We included children that had experienced six or more ARTIs in the prior 12 months, because less than six ARTIs per year is considered normal in children [1-4].

Table 1 Frequency of upper and lower acute respiratory tract infections (ARTIs), specific diagnoses, and corresponding treatment, in pediatric patients that attended day-care centers or preschool estimated by the expert panel

\begin{tabular}{|c|c|c|c|}
\hline ARTI parameters & Frequency & Treated without Antibiotics & Treated with Antibiotics \\
\hline \multicolumn{4}{|l|}{ Upper ARTIs (number per year) } \\
\hline$<3$ & $10 \%$ & $10-30 \%$ & $70-90 \%$ \\
\hline 3 to 6 & $30-50 \%$ & $10-30 \%$ & $70-90 \%$ \\
\hline 6 to 10 & $50-80 \%$ & $10-30 \%$ & $70-90 \%$ \\
\hline$>10$ & $10 \%$ & $10-30 \%$ & $70-90 \%$ \\
\hline \multicolumn{4}{|l|}{ Lower ARTIs (number per year) } \\
\hline 1 & $97 \%$ & $0 \%$ & $100 \%$ \\
\hline 2 to 3 & $1 \%$ & $0 \%$ & $100 \%$ \\
\hline 4 to 6 & $1 \%$ & $0 \%$ & $100 \%$ \\
\hline 6 to 10 & $1 \%$ & $0 \%$ & $100 \%$ \\
\hline \multicolumn{4}{|l|}{ Type of upper ARTI } \\
\hline $\begin{array}{l}\text { Simple upper ARTI (Common cold, rhinopharyngitis, } \\
\text { tonsillitis, pharyngotonsillitis) }\end{array}$ & $70 \%$ & $20-30 \%$ & $70-80 \%$ \\
\hline Otitis media & $25 \%$ & $20 \%$ & $80 \%$ \\
\hline Rhinosinusitis & $5 \%$ & $10 \%$ & $90 \%$ \\
\hline
\end{tabular}




\section{Study hypothesis}

We hypothesized that the immunostimulant, OM-85, would be cost-effective in the prevention of ARTIs in susceptible preschool-age children that attended day-care centers or preschools in Mexico.

\section{Study perspective}

We assumed an institutional perspective, where the institution was responsible for patient medical care, medications, and the salary of parents that missed days of work to attend to their sick children. When a child is sick, he/ she is not allowed to attend the day-care-center/preschool. One of the parents (mainly mothers) must take to the child to a social medicine clinic to obtain medical care and a certificate of permission to be absent from the job while taking care of the child. The total earnings pertaining to the absent work days are covered by the institution.

\section{Time horizon; study period}

The study period covered six months during the fall and winter seasons of $2017-2018$ as it explained the most of

Table 2 Cost of one treatment for acute respiratory tract infection, without or with antibiotics estimated by the expert panel

\begin{tabular}{|c|c|c|}
\hline Medication & Age: Treatment time (patient weight) & Treatment cost (\$MXN) \\
\hline \multicolumn{3}{|l|}{ Treatments without antibiotics } \\
\hline \multicolumn{3}{|l|}{ Antihistamine combinations } \\
\hline Antifludes ${ }^{\mathrm{TM}}$ & $2-6$ years: $3-5$ days & $\$ 68.95$ \\
\hline Sensibit $^{\mathrm{TM}}$ & $2-6$ years: $3-5$ days & $\$ 202.50-\$ 79.50$ \\
\hline $\mathrm{LMG}^{\mathrm{TM}}$ & $2-6$ years: $3-5$ days & $\$ 69.00$ \\
\hline \multicolumn{3}{|c|}{ Antipyretics/ Anti-inflammatory drugs } \\
\hline \multirow[t]{3}{*}{ Ibuprofen } & 2 years: $3-5$ days & $\$ 79.50-\$ 34.50$ \\
\hline & 4 years: $3-5$ days & $\$ 159.00-\$ 69.00$ \\
\hline & 6 years: $3-5$ days & $\$ 159.00-\$ 69.00$ \\
\hline \multirow[t]{3}{*}{ Paracetamol } & 2 years: $3-5$ days & $\$ 80.00-\$ 34.50$ \\
\hline & 4 years: $3-5$ days & $\$ 80.00-\$ 34.50$ \\
\hline & 6 years: $3-5$ days & $\$ 160.00-\$ 69.00$ \\
\hline \multirow[t]{3}{*}{ Nimesulide } & 2 years: $3-5$ days & $\$ 223.50-\$ 86.95$ \\
\hline & 4 years: $3-5$ days & $\$ 223.50-\$ 86.95$ \\
\hline & 6 years: $3-5$ days & $\$ 447.00-\$ 173.90$ \\
\hline \multicolumn{3}{|l|}{ Treatment with antibiotics } \\
\hline \multirow[t]{3}{*}{ Amoxicillin } & 2 years: $7-10$ days $(12.5 \mathrm{~kg})$ & $\$ 199.00-\$ 61.95$ \\
\hline & 4 years: $7-10$ days $(16$ kg) & $\$ 199.00-\$ 61.95$ \\
\hline & 6 years: $7-10$ days $(21 \mathrm{~kg})$ & $\$ 298.50-\$ 123.90$ \\
\hline \multirow[t]{3}{*}{ Amoxicillin + Clavulanic acid } & 2 years: $7-10$ days $(12.5 \mathrm{~kg})$ & $\$ 250.95-\$ 85.95$ \\
\hline & 4 years: $7-10$ days ( 16 kg) & $\$ 250.95-\$ 171.90$ \\
\hline & 6 years: $7-10$ days $(21 \mathrm{~kg}$ ) & $\$ 501.90-\$ 171.90$ \\
\hline \multirow[t]{3}{*}{ Cefuroxime } & 2 years: $7-10$ days $(12.5 \mathrm{~kg})$ & $\$ 520.5-275.90$ \\
\hline & 4 years:7-10 days $(16 \mathrm{~kg})$ & $\$ 1041.00-275.90$ \\
\hline & 6 years: $7-10$ days $(21$ kg) & $\$ 1041.00-413.85$ \\
\hline \multirow[t]{3}{*}{ Cefalexin } & 2 years: $7-10$ days $(12.5 \mathrm{~kg})$ & $\$ 655.00-\$ 159.90$ \\
\hline & 4 years:7-10 days (16 kg) & $\$ 655.00-\$ 159.90$ \\
\hline & 6 years: $7-10$ days $(21$ kg) & $\$ 982.5-\$ 239.85$ \\
\hline \multirow[t]{3}{*}{ Clarithromycin } & 2 years: $7-10$ days $(12.5 \mathrm{~kg})$ & $\$ 494.95-\$ 241.40$ \\
\hline & 4 years:7-10 days ( 16 kg) & $\$ 494.95-\$ 241.50$ \\
\hline & 6 years: $7-10$ days $(21$ kg) & $\$ 989.9-\$ 483.00$ \\
\hline \multirow[t]{3}{*}{ Cephalosporin (3rd Generation) } & 2 years: $7-10$ days ( $12.5 \mathrm{~kg})$ & $\$ 486.50-\$ 514.00$ \\
\hline & 4 years:7-10 days (16 kg) & $\$ 637.00-\$ 685.95$ \\
\hline & 6 years: $7-10$ days $(21 \mathrm{~kg})$ & $\$ 637.00-\$ 685.95$ \\
\hline
\end{tabular}


ARTIs in the year. Discount rate was not applied, because the short period.

The children were followed for six months, starting at the beginning of the fall season and the initiation of the immunostimulant treatment. The modeling period corresponded to the period that the immunostimulant was expected to provide the protective effect demonstrated in clinical trials. It covered the time interval associated with the highest ARTI incidence; 60 to $70 \%$ of all ARTIs occurred in the fall and winter seasons (expert panel).

\section{Methods}

We created hypothetical patients, based on the incidence and costs of children that attended day-care-centers/preschools reported by the panel of experts. The incidence of ARTIs and the costs of treatment are described below.

We collected data on the incidence of ARTIs, the kind of ARTIs, and the treatment costs from a group of physicians assigned to the Hospital Infantil de México, "Federico Gómez"; All costs are expressed in Mexican pesos $(\$ M X N)$, valued in October 2017. The exchange rate was

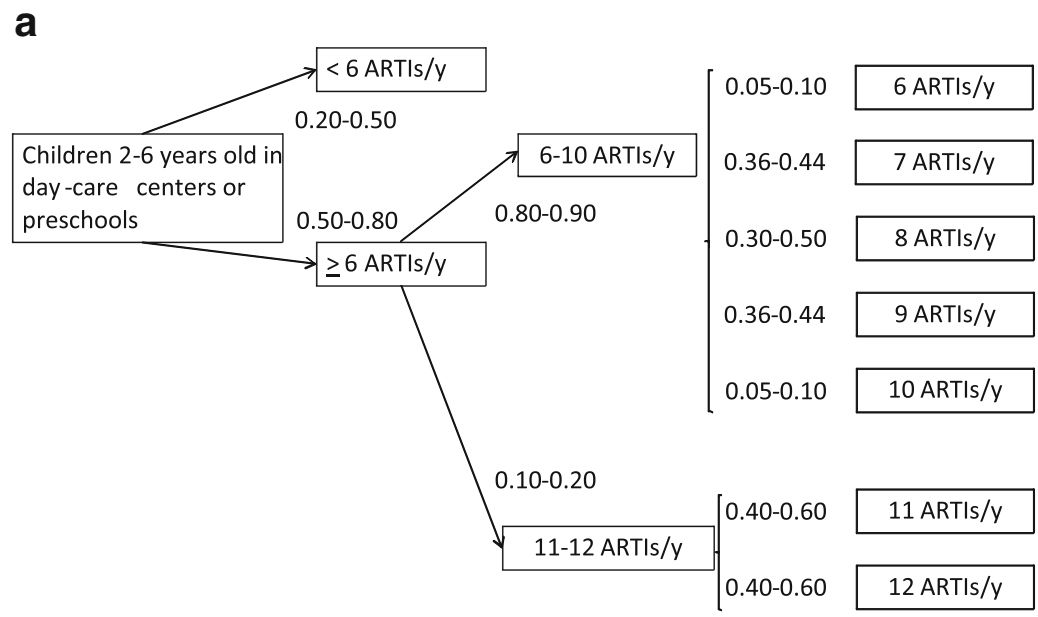

b

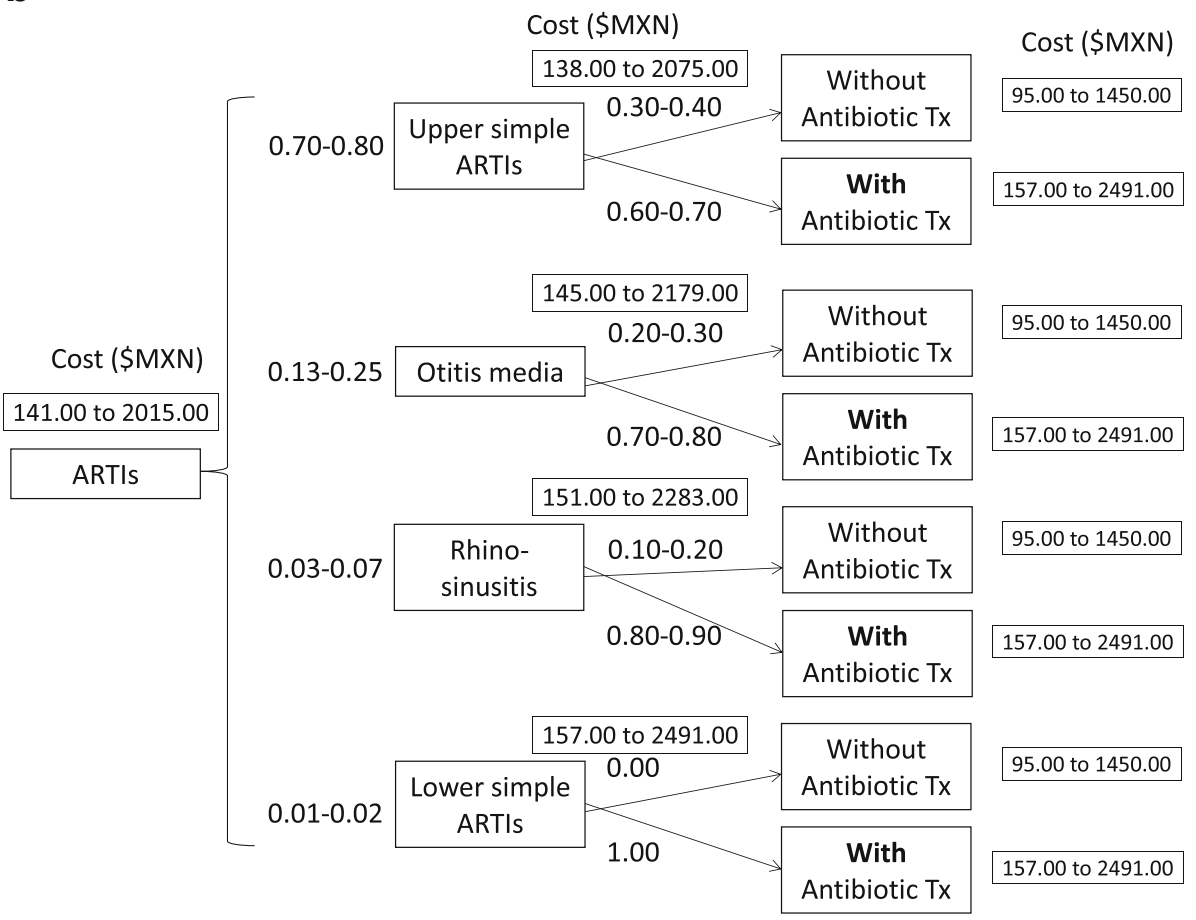

Fig. 1 Decision tree analyses for frequencies and types of ARTIs and the typical treatments in 2-6year-old children that attended day-care centers or preschools. (a) Frequency of ARTIs; (b) differential diagnosis of ARTIs, their treatments, and the costs of treatment. ARTI: acute respiratory tract infection; Tx: treatment 
$\$ 20.00$ pesos per one American dollar. The purchase power parity (PPP) reported for \$MXN in 2017 was 9.041 (https://data.oecd.org/conversion/purchasing-power-parities-ppp.htm).

We next used these data to elaborate two decision trees, as they best reflected the current occurrence of the ARTIs in the population. The first included the probabilities and number of ARTIs in the group of interest; the second included the probabilities of the different kinds of ARTIs and their treatment costs. We determined the efficacy of OM-85 by performing a meta-analysis of the double-blind, placebo-controlled trials conducted in Mexico. We also considered other data, including the cost range of ARTI treatments, which included the OM- 85 doses, parental absenteeism, and treatments for adverse events. A cost model was used to calculate the cost, cost effectiveness, and incremental cost-effectiveness. We employed the bootstrap method to create 1000 replications for a group of 2000 subjects, based on the ranges of probability for each event and the implied range of costs. Bootstrap estimations were used to calculate the mean, median, range, and quartiles of pharmacoeconomic parameters. The results were plotted to evaluate cost-effectiveness (scatter-plots; incremental cost vs. incremental effectiveness plots show the mean differences in the costs and outcomes of OM-85 treatment compared to typical treatments) and cost-effectiveness vs. acceptability (curves; probability of cost-effectiveness vs. willingness to pay curves show the probability that OM-85 treatment would be cost-effective, based on how much the payer is willing to pay).

\section{Results}

Table 1 shows the annual frequency of upper and lower ARTIs in children aged 2 to 6 years that attended day-care centers or preschools, according to data acquired from the expert panel (including five pediatric allergists and five pediatric otorhinolaryngologists that worked at the Hospital Infantil de Mexico Federico Gomez and also practiced in private offices). The different diagnoses and their respective treatments were described by the expert panel. The expert panel estimated that 60 to $70 \%$ of all ARTIs occurred in the fall and winter seasons. In the population of interest, children with ARTIs spent 5 to 7 days out of day care/preschool, and one of the parents was allowed to take days off work to care for their ill children; the full salary that accrued while the parent cared for the child was covered by the institution.

The estimated costs for the ARTI treatments, without and with antibiotics, are shown in Table 2.

The lowest and highest estimates for direct costs for one ARTI treated without antibiotics were 95.00 \$MXN (Mexican pesos) and $1450.00 \$ M X N$, respectively; the corresponding costs for a treatment with antibiotics were $157.00 \$ M X N$ and $2491.00 \$ M X N$, respectively.
The cost of one parent missing work for one ARTI ranged from 630.00 \$MXN to 2100.00\$MXN. Pediatric OM-85 (10 capsules, $3.5 \mathrm{mg}$ each) cost 430 \$MXN at the drugstore. The complete treatment consisted of 30 capsules; thus, the total cost was $1290 \$ M X N$.

We also investigated adverse events. The Cochrane systematic review indicated that the use of immunostimulants to prevent ARTIs was associated with 30 gastrointestinal and 7 dermic events per 1000 treated patients. We assigned a mean cost of $500.00 \$ M X N$ per adverse event.

Figure 1 shows the decision tree analyses of ARTI frequencies, types, and typical treatments. With these values, we calculated the ranges of probabilities and costs, which were used to generate 1000 estimations with the bootstrap method (Table 3).

Table 3 Probabilities of ARTIs in 2-6year-old children at daycare centers or preschools and estimated costs, for use in the bootstrap method estimated by the expert panel

\begin{tabular}{|c|c|}
\hline Event & Range \\
\hline$\geq 6 \mathrm{ARTIS} / \mathrm{y}$ & $0.50-0.80$ \\
\hline 6-10 ARTIs/y & $0.80-0.90$ \\
\hline 11-12 ARTIs/y & $0.10-0.20$ \\
\hline 6 ARTIS/Y & $0.05-0.10$ \\
\hline $7 \mathrm{ARTIS} / \mathrm{Y}$ & $0.36-0.44$ \\
\hline 8 ARTIS/Y & $0.30-0.50$ \\
\hline 9 ARTIS/Y & $0.36-0.44$ \\
\hline $10 \mathrm{ARTIS} / \mathrm{Y}$ & $0.05-0.10$ \\
\hline $11 \mathrm{ARTIS} / \mathrm{Y}$ & $0.40-0.60$ \\
\hline $12 \mathrm{ARTIS} / \mathrm{Y}$ & $0.40-0.60$ \\
\hline ARTIs in Fall-Winter Season & $0.60-0.70$ \\
\hline Simple acute lower ARTIs & $0.01-0.02$ \\
\hline Simple acute upper ARTls & $0.70-0.80$ \\
\hline Acute otitis media & $0.13-0.25$ \\
\hline Acute rhinosinusitis & $0.03-0.07$ \\
\hline Tx with antibiotics for simple acute lower ARTIs & 1 \\
\hline Tx without antibiotics for simple acute upper ARTIs & $0.30-0.40$ \\
\hline Tx with antibiotics for simple acute upper ARTIs & $0.60-0.70$ \\
\hline Tx without antibiotics for acute otitis media & $0.20-0.30$ \\
\hline Tx with antibiotics for acute otitis media & $0.70-0.80$ \\
\hline Tx without antibiotics for acute rhinosinusitis & $0.10-0.20$ \\
\hline Tx with antibiotics for acute rhinosinusitis & $0.80-0.90$ \\
\hline Cost of Tx without antibiotics (\$MXN) & $95-1450$ \\
\hline Cost of Tx with antibiotics (\$MXN) & $157-2491$ \\
\hline Cost of parent job absenteeism (\$MXN) & $630-2100$ \\
\hline OM-85 effectiveness (ARTI reduction) & $0.38-0.55$ \\
\hline Cost of OM-85 (\$MXN) & $258-430$ \\
\hline Cost of OM-85 adverse events (\$MXN) & $11.1-22.2$ \\
\hline
\end{tabular}

Values are frequencies, unless otherwise indicated. ARTI acute respiratory tract infection, $T x$ treatment 
The mean $( \pm$ SD) incidences of ARTIs were $5.59 \pm$ 0.29 without immunostimulants and $2.97 \pm 0.32$ with OM-85, during the study period. The mean (25th, 75th percentile) direct costs of ARTIs were 1140.80 (742.10, 1527.80) MXN\$ [57.04 (37.11, 76.39) US\$; 515.70 $(335.47,690.64)$ \$MXN adjusted by PPP] without immunostimulants and $970.60(746.90,1178.50)$ \$MXN [48.53 (37.35, 58.93) US\$; 438.76 (337.64; 532.74) \$MXN adjusted by PPP] with OM-85, with a mean increment of $-170.20(-341.50,14.90)$ \$MXN $[-8.51(-17.08,0.75)$ US\$; $-76.94(-154.38,6.74)$ \$MXN adjusted by PPP], and a mean cost-effectiveness of $-358.80(-729.50$, 33.10) \$MXN. [- $17.94(-36.48,1.66)$ US\$; -162.20 ($329.77,14.96)$ \$MXN adjusted by PPP]. Part of the cost reduction was ascribed to the reduced use of medications, particularly antibiotics. The direct costs plus the cost of one parent missing work to care for the child with ARTI were 2515.10 (2056.50, 3003.10) \$MXN [125.76 (102.83, 150.16) US\$; 1136.95 (929.64, 1357.55) \$MXN adjusted by PPP] without immunostimulant and 1704.10 (1442.90, 1976.20) \$MXN [85.21 (72.15, 98.81) US\$; 770.34 $(652.26,893.34)$ \$MXN adjusted by PPP] with OM-85. The increment was -811.00 (-1365.80, 279.00) \$MXN [- 40.55 (-68.29, - 13.95) US\$; -366.61 $(-617.41,-126.12) \$ M X N$ adjusted by PPP], and the cost-effectiveness was -1737.80 (-2847.30, - 586.70) \$MXN.[- 86.89 (-142.37, - 29.34) US\$; $-785.57 \quad$ ($1287.12,-265.22) \$ M X N$ adjusted by PPP]. In all conditions, OM-85 showed cost-effectiveness. Moreover, the OM-85 group showed cost savings in over $70 \%$ of cases for direct costs (See Table 4).
Figure 2 shows cost-effectiveness scatter-plot and cost-effectiveness acceptability curves, both for direct costs and direct costs plus absenteeism cost. The cost-effectiveness scatter-plot for direct costs showed that OM-85 provided positive incremental effectiveness for all ARTI conditions. Moreover, OM- 85 provided cost savings (negative incremental costs) for more than $70 \%$ of conditions. The cost-effectiveness scatter-plot for the direct costs plus the parent absenteeism cost showed that OM-85 provided positive incremental effectiveness for all ARTI conditions, and in 90\% of ARTI conditions, OM- 85 provided cost savings.

The acceptability curve of direct costs showed that the probability of achieving cost-effectiveness was above $70 \%$, even when the willingness to pay was zero; it reached $80 \%$, when the willingness to pay was between 100.00 and $150.00 \$ M X N$. Moreover, the acceptability curve of direct costs plus absenteeism cost showed that the probability of cost-effectiveness was above $80 \%$, when the willingness to pay was zero, and it rose to $90 \%$, when the willingness to pay was $250.00 \$ M X N$.

\section{Discussion}

The use of immunostimulants for the prevention of ARTIs in children has been controversial for several years [19]. Yet, systematic reviews [17-19] have supported their effectiveness with evidence of moderate quality. It was shown that immunostimulants could reduce ARTI frequency by nearly $40 \%$, but they also provoked secondary effects, with an adverse event rate (gastrointestinal and dermic events) of 37/1000 treated patients [17].

Table 4 Descriptive statistics for the pharmacoeconomic variables used in this study with data from meta-analysis and estimated by the expert panel

\begin{tabular}{|c|c|c|c|c|c|c|c|c|c|}
\hline Assessment & Mean & SEM & Median & SD & Variance & Min & Max & 25th Pctl & 75th Pctl \\
\hline \multicolumn{10}{|l|}{ OM-85 } \\
\hline Effectiveness & 0.466 & 0.002 & 0.467 & 0.049 & 0.002 & 0.38 & 0.55 & 0.424 & 0.508 \\
\hline Tx without IS, n & 5.6 & 0.01 & 5.59 & 0.29 & 0.09 & 4.93 & 6.3 & 5.37 & 5.85 \\
\hline Tx with OM-85, n & 2.99 & 0.01 & 2.97 & 0.32 & 0.1 & 2.31 & 3.83 & 2.74 & 3.24 \\
\hline Incremental ARTIs, $n$ & -2.61 & 0.01 & -2.6 & 0.31 & 0.09 & -3.4 & -1.9 & -2.82 & -2.38 \\
\hline \multicolumn{10}{|l|}{ Direct Costs (\$MXN) } \\
\hline Tx without IS & 1140.8 & 15.1 & 1124.2 & 478.7 & 229,163 & 180 & 2149.1 & 742.1 & 1527.8 \\
\hline Tx with OM-85 & 970.6 & 8.5 & 965.1 & 268.8 & 72,235 & 370.6 & 1647.9 & 746.9 & 1178.5 \\
\hline Incremental & -170.2 & 7.4 & -154.6 & 235.1 & $55,282.5$ & -839.4 & 316.1 & -341.5 & 14.9 \\
\hline Cost-Effectiveness & -358.8 & 15.6 & -326.7 & 493.1 & 243,194 & -1528.9 & 756.2 & -729.5 & 33.1 \\
\hline \multicolumn{10}{|c|}{ Direct Cost + Absenteeism (\$MXN) } \\
\hline Tx without IS & 2515.1 & 20.5 & 2495.4 & 648.1 & 419,984 & 944.5 & 4140.4 & 2056.5 & 3003.1 \\
\hline Tx with OM-85 & 1704.1 & 11.8 & 1681.2 & 373 & 139,107 & 853.9 & 2758.8 & 1442.9 & 1976.2 \\
\hline Incremental & -811 & 23.3 & -790 & 737.8 & 544,411 & -2722.1 & 1490.8 & -1365.8 & -279 \\
\hline Cost-Effectiveness & -1737.8 & 50.8 & -1662.5 & 1606.4 & $2,580,387$ & -6705.7 & 3566.4 & -2847.3 & -586.7 \\
\hline
\end{tabular}

Absenteeism, parent missing work to care for a sick child; ARTIs acute respiratory tract infections, IS immunostimulant, Max maximum, Min minimum, PctI percentile, SD standard deviation, SEM standard error of the mean, $T x$ treatment for acute respiratory tract infection 


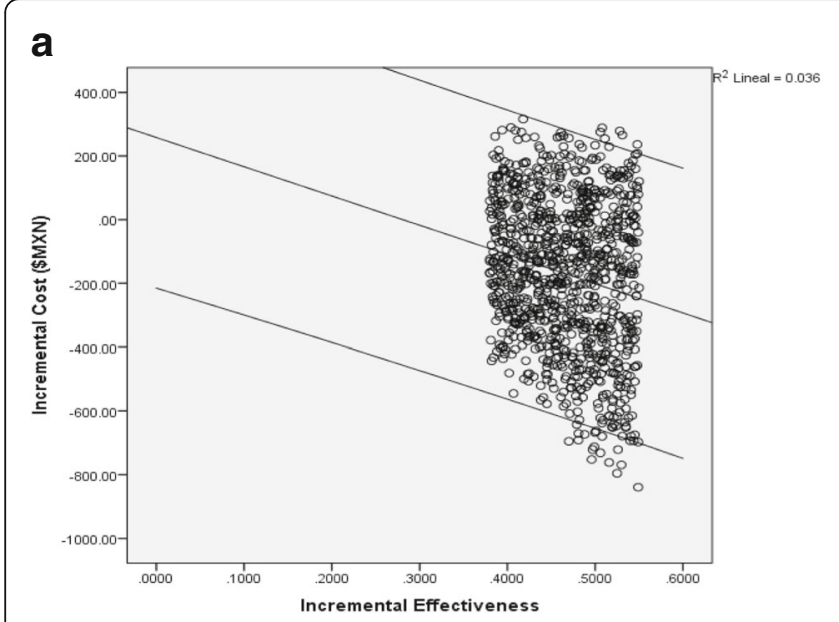

b

C
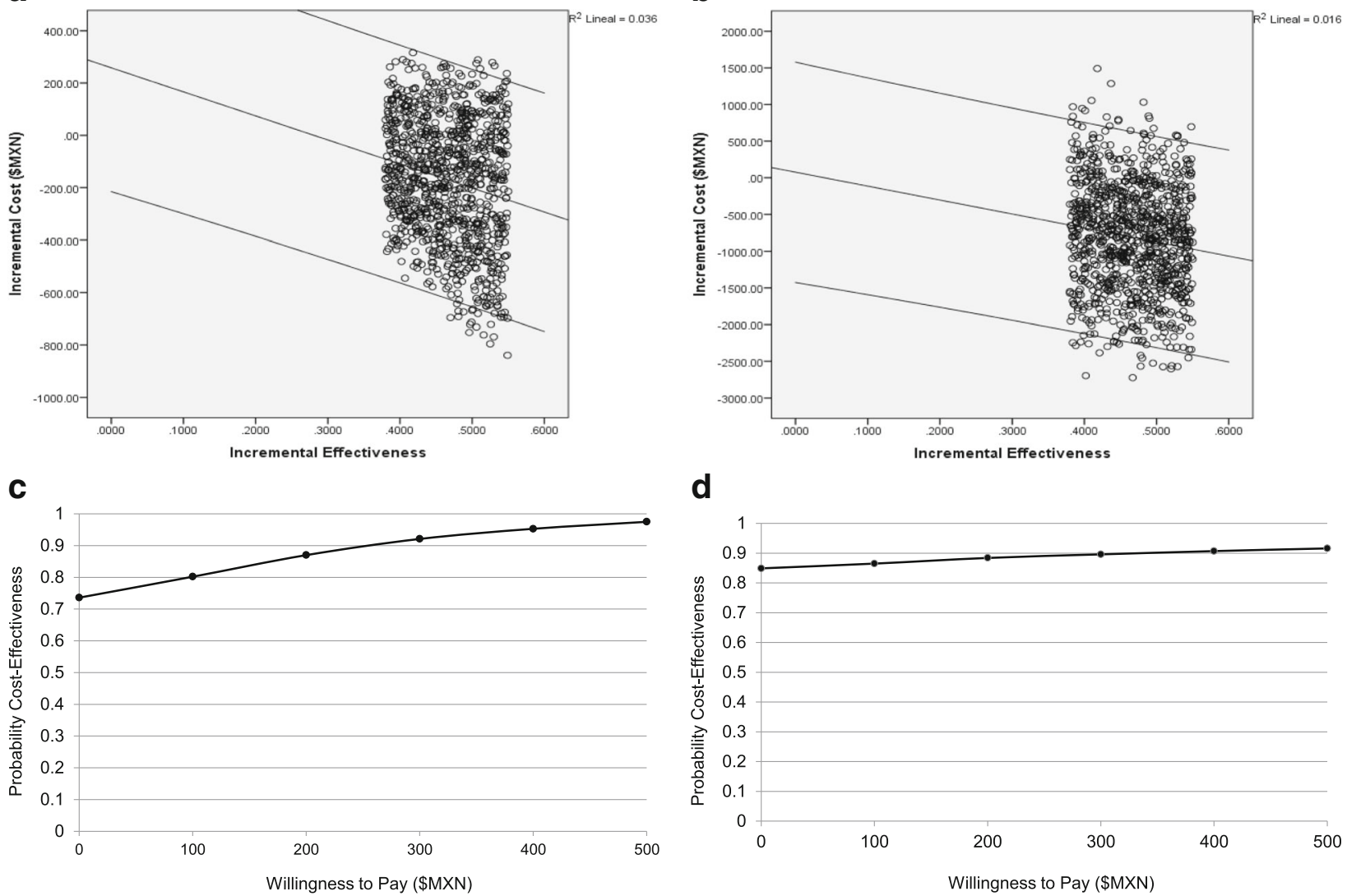

d

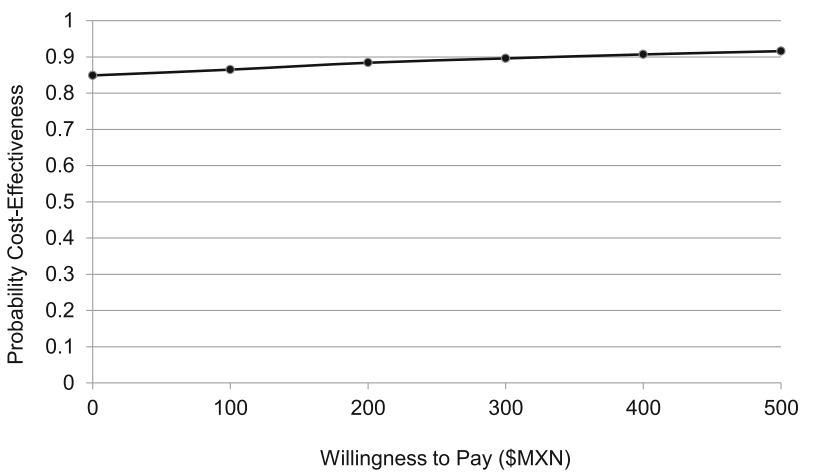

Fig. 2 Cost-effectiveness and acceptability of OM-85 treatment for acute respiratory tract infection. (a, b) Incremental cost vs. incremental effectiveness plots show the mean differences in the costs and outcomes of OM-85 treatment compared to typical treatments, based on data from 1000 bootstrap replicates. Negative costs represent savings with OM-85 compared to typical treatments. (a) Direct costs; (b) direct costs plus parental absenteeism cost (i.e., the cost of one parent missing work to care for the child). Lines show the mean and 95\% confidence intervals; (c, d) Probability of cost-effectiveness vs. willingness to pay curves show the probability that OM-85 treatment would be cost-effective, based on how much the payer is willing to pay. (c) Direct costs; (d) direct costs plus parental absenteeism cost

Previous pharmacoeconomic evaluations have studied immunostimulants for preventing pediatric ARTIs [2022]. For example, Pessey 2003 [20] evaluated the pharmacoeconomic value of using OM-85 for the prevention of rhinopharyngitis in French children, based on the low efficacy reported in three European studies $[11,13,16]$ and the cost structure of the French Social Security system. They performed a sensitivity analysis with extreme values, in a model constructed without generating a cloud of estimations. According to their study, the cost of one episode of acute rhinosinusitis was $€ 49.39$ (value in the year 2000) and the use of OM-85 would prevent 1.52 infections over six months, with a savings of $€ 67.83$ (range: $€ 6.28$ to $€ 303.64$ ). They concluded that OM-85 was a cost-effective intervention.

Another study, based on conditions in Italy [21], found that a complete cycle of OM-85 treatment could reduce the number of upper ARTIs by 1.60 /pediatric patient (ages 6 months to 19 years) over six months. This reduction in upper ARTIs could save €107.42/patient, from the family's perspective; $€ 231.26$, from the community perspective; and $€ 48.52$, from the National Health System perspective. They estimated that the use of OM-85 in ARTI prevention would be cost-effective, when more than $7 \%$ of upper ARTIs were prevented and the total cost of treating one upper ARTI was greater than $€ 10.00$. Another Italian pharmacoeconomic evaluation [22] estimated that a complete course of OM-85 would reduce the number of ARTIs by 1.2 /pediatric patient in a six-month period. This would achieve a savings of $€ 40.30 /$ patient (2015 prices), from the perspective of the National Health Service, and the savings would be $€ 182.99 /$ patient, from the perspective of the community.

The present study differed from previous studies in several points. We investigated the immunostimulant effect on day-care-center/preschool children, a population at high risk of contracting ARTIs. We focused on patients with six or more ARTIs in the 12 months prior to 
the study. The study took into account the incidence of the different kinds of ARTIs, their typical treatments, and the corresponding costs. However, the present study did not include extra costs for laboratory tests and other procedures, because they are not typically ordered for this type of patient. We employed a cloud of 1000 estimations, which allowed a better sensitivity analysis.

The main limitation of the present study was that the data on ARTI frequencies, types, typical treatments, and costs were obtained from a panel of pediatricians that worked in a public hospital and also in private practice. Alternative means for retrieving this information might be to compile information from medical charts or to perform a formal field study.

The present study focused on the individual impact of ARTI prevention from the institutional point of view. Future clinical studies and pharmacoeconomic evaluations should include the implications for day-care centers and preschools; they should include both the community and individual points of view; and they should include the impact of the results on the National Health System.

The results of the present pharmacoeconomic evaluation were consistent with previous observations found in an open study of orphan homes in Baja California, Mexico [23] and in a double-blind placebo-controlled study conducted in the Girl's Home in Mexico City [10]. Those studies also reported that immunostimulant treatments reduced the number of ARTIs in treated participants and reduced the use of medications, particularly antibiotics.

\section{Conclusions}

We found that the immunostimulant, OM-85, was a cost-effective intervention for the prevention ARTIs in high risk children, aged 2 to 6 years, that attended day-care centers or preschools. This intervention was particularly cost-effective, when the costs of parental job absenteeism were also considered.

\section{Abbreviations}

\$MXN: Mexican pesos; €: Euros; ARTI: Acute respiratory tract infection;

Cl: Confidence interval; RR: Relative risk; SD: standard deviation; US\$: USA dollars

\section{Acknowledgements}

We wish to acknowledge the contributions of Dr. Enrique Gómez-Morales and Dr. Juan Jesús Vargas-Valencia to the present study. Editing and proofreading of the manuscript was realized by San Francisco Edit.

\section{Funding}

Allergy and Immunology Service, Hospital Infantil de Mexico "Federico Gomez".

\section{Availability of data and materials}

Not applicable; data are included in the tables of the article.

\section{Authors' contributions}

$A B$; wrote the protocol, conducted the statistical analyses, prepared the manuscript. BEDRN; created the decision trees, obtained the costs, prepared the manuscript. Both authors read and approved the final manuscript.

\section{Competing interests}

Dr. Arturo Berber declares he has competing interests.

Dr. Blanca E. Del-Rio-Navarro has received honoraria from MSD, Astra, Novartis, Grunenthal and Sanofi.

\section{Publisher's Note}

Springer Nature remains neutral with regard to jurisdictional claims in published maps and institutional affiliations.

\section{Author details}

${ }^{1}$ Fundación para el Avance de la Ciencia, Oasis 14, CP 02080 Mexico City, Mexico. ${ }^{2}$ Allergy \& Immunology Service, Hospital Infantil de Mexico "Federico Gomez", Dr. Marquez 162, CP 06720 Mexico City, Mexico.

Received: 21 September 2018 Accepted: 16 April 2019

Published online: 07 May 2019

\section{References}

1. Ochoa Sangrador C, Barajas Sánchez MV, Muñoz Martín B. Relationship between child day-care attendance and acute infectious disease. A systematic review. Rev Esp Salud Publica. 2007:81:113-29.

2. Flores-Hernandez S, Reyes-Morales H, Perez-Cuevas R, et al. The day care center as a risk factor for acute respiratory infections. Arch Med Res. 1999; 30:216-23.

3. Enserink $\mathrm{R}$, Lugnér $\mathrm{A}$, Suijkerbuijk $\mathrm{A}$, et al. Gastrointestinal and respiratory illness in children that do and do not attend child day care centers: a costof-illness study. PLoS One 2014;9(8):e104940. doi: https://doi.org/10.1371/ journal.pone.0104940. eCollection 2014.

4. Delpiano L, Kabalán P, Díaz C, et al. Características y costos directos de infecciones respiratorias agudas en niños de guarderías infantiles [acute respiratory infections in children of day care center: characteristics and costs]. Rev Chil Infect. 2006;23(2):128-33.

5. Ahrens J. Multicentre double-blind clinical trial with broncho-vaxom in children. Therapiewoche. 1984;34:3469-75.

6. Collet JP, Ducruet T, Kramer MS, et al. Stimulation of nonspecific immunity to reduce the risk of recurrent infections in children attending day-care centers. The Epicreche Research Group Pediatr Infect Dis J. 1993;12:648-52.

7. Del Río Navarro BE, Sienra Monge JJL, Berber A, et al. Use of OM-85 BV in children suffering from recurrent respiratory tract infections and subnormal lgG subclass levels. Allergol Immunopathol (Madr). 2003;31:7-13.

8. Gomez Barreto D, De la Torre C, Alvarez A, et al. Safety and efficacy of OM85-BV plus amoxicillin/clavulanate in the treatment of subacute sinusitis and the prevention of recurrent infections in children [Seguridad y eficacia de OM-85-BV más amoxicilina/clavulanato en el tratamiento de la sinusitis subaguda y prevención de infecciones recurrentes en niños]. Allergol Immunopathol (Madr). 1998;26:17-22

9. Gutiérrez-Tarango MD, Berber A. Safety and efficacy of two courses of OM$85 \mathrm{BV}$ in the prevention of respiratory tract infections in children during 12 months. Chest. 2001;119:1742-8.

10. Jara-Perez $\mathrm{JV}$, Berber A. Primary prevention of acute respiratory tract infections in children using a bacterial immunostimulant: a double-masked, placebo-controlled clinical trial. Clin Ther. 2000;22:748-59.

11. Maestroni GJ, Losa GA. Clinical and immunobiological effects of an orally administered bacterial extract. Int J Immunopharmacol. 1984:6:111-7.

12. Martin du Pan RE, Martin du Pan RC. Clinical study concerning the prevention of infections of the upper respiratory tract of preschool children. Schweiz Rundsch Med Prax. 1982;71:1385-9.

13. Paupe J. Immunotherapy with an oral bacterial extract (OM-85 BV) for upper respiratory infections. Respiration. 1991;58:150-4.

14. Schaad UB, Farine JC, Fux T. Prospective placebo-controlled double-blind study using a bacterial lysate in infections of the respiratory tract and ENT region in children [prospective placebo-kontrollierte Doppelblindstudie mit einem Bakterienlysat bei Infektionen der Atemwege und des ORL-Bereiches im Kindesalter]. Helv Paediatr Acta. 1986;41:7-17.

15. Schaad UB, Mutterlein $\mathrm{R}$, Goffin $\mathrm{H}$, et al. Immunostimulation with OM-85 in children with recurrent infections of the upper respiratory tract: a doubleblind, placebo-controlled multicenter study. Chest. 2002;122:2042-9.

16. Zagar S, Lofler-Badzek D. Broncho-vaxom in children with rhinosinusitis: a double-blind clinical trial. ORL J Otorhinolaryngol Relat Spec. 1988:50:397_ 404. 
17. Del-Rio-Navarro BE, Espinosa-Rosales FJ, Flenady V, Sienra-Monge JJ. Cochrane review: Immunostimulants for preventing respiratory tract infection in children. Evidence-Based Child Health: A Cochrane Review Journal. 2012;7:629-717.

18. De-la-Torre-Gonzalez C, Pacheco-Rios A, Escalante-Dominguez AJ, et al. Comparative metaanalysis of immunostimulant agents used in pediatric patients in Mexico [Metaanalisis comparativo de los inmunoestimulantes utilizados enpediatría en México]. Rev Alerg Mex. 2005;52:25-38.

19. Del-Rio-Navarro BE, Espinosa-Rosales FJ, Flenady V, et al. Immunostimulants for preventing respiratory tract infection in children. Cochrane Database Syst Rev. Issue 4. Art. No.: CD004974. DOl: https://doi.org/10.1002/14651858. CD004974.pub2.

20. Pessey JJ, Migas F, Arnould B, et al. Prevention of recurrent rhinopharyngitis in at-risk children in France: a cost-effectiveness model for a nonspecific immunostimulating bacterial extract (OM-85 BV). Pharmacoeconomics. 2003; 21:1053-68.

21. Zaniolo O, Pradelli L, Eandi M. OM-85, cost/effectiveness, upper respiratory tract infections (URTIs) [Costo/efficacia della prevenzione di infezioni alle prime vie aeree mediante un estratto batterico immunostimolante aspecifico (OM-85)] Farmeconomia e percorsi terapeutici. 2005; 6 (3): 169-184.

22. Ravasio R. Economic analysis of the Immunostimulant $\mathrm{OM}-85$ for the prevention of Paediatric recurrent upper respiratory tract infections. Glob Regional Health Technol Assess. 2015;2(3):135-42.

23. Field J, Gomez-Barreto D, Del-Rio-Navarro BE, et al. Use of OM-85 BV in primary prevention of acute respiratory tract infections in children in orphanages. Curr Ther Res Clin Exp. 1998;59:407-18.

Ready to submit your research? Choose BMC and benefit from:

- fast, convenient online submission

- thorough peer review by experienced researchers in your field

- rapid publication on acceptance

- support for research data, including large and complex data types

- gold Open Access which fosters wider collaboration and increased citations

- maximum visibility for your research: over $100 \mathrm{M}$ website views per year

At $\mathrm{BMC}$, research is always in progress.

Learn more biomedcentral.com/submissions 